\title{
The Forensic Psychiatric Expertise in Romania: The Legal Medicine Implications
}

\author{
Cristina Gabriela Șchiopu \\ Institute of Legal Medicine, Iași, Romania, schiopu_cristina_gabriela@yahoo.ro
}

\begin{abstract}
The Penal Code of Romania, describes a list of paragraphs about the criminal offences made by people with unknown or acute mental illness or in circumstances that can affect the judgment of the one directly involved. In these cases, the only way to investigate the state of mind of a criminal in the moment that he produced that offence, is by analysing his mental capacity, his reactions in those circumstances, to investigate his social and family history and by interviewing him in front of the medico-legal psychiatric committee after a clinical and paraclinical assessment. The felon is brought by a police or a prosecutor order in front of the committee, after the investigations demonstrated that he or she is for sure the criminal offender and there are no longer suspicions about the identity of the felon. The offender can be brought for forensic psychiatric examination if he is already known with a mental illness or if, during the investigations, the police observes suspect changes of the behavior. There are also some crimes, the severe ones, that are mandatory to be investigated psychiatrically. The procedure is very complex but the investigations often depend entirely on the conclusions of the medico-legal psychiatric expertise.
\end{abstract}

KEYWORDS: discernment, dissimulation, expertise, forensic, mental illness

\section{Introduction}

The legal medicine practice in Romania involves different types of expertise such as: investigation of suspicious or violent deaths, expertise of different types of aggressions on living people, the expertise on medical errors and the judiciary psychiatric expertise that is conducted on two different directions: the civil expertise which involves investigating the mental capacity of exercising civil rights and the penal expertise which involves investigating the state of mind of people who commit different crimes, at the moment that he produced that offence. The penal psychiatric expertise is a complex procedure by being a retrospective analysis with a high grade of responsibility for the specialists involved in the expertise.

\section{The legal psychiatric expertise}

The legal psychiatric expertise in Romania is regulated by the Penal Procedure Code at the Article 184. According to this article, the procedure is an interdisciplinary one. That means that the psychiatric analysis will be made by a committee consisting of a legal medicine doctor, a psychologist and two psychiatrists. The expertise will be conducted in a psychiatric institute, where the felon will be hospitalized before bringing him to the committee for the main interview. During the hospitalization, he will be subjected to clinical assessment which will consolidate the objectivity of the expertise.

According to the Penal Procedure Code (2010), the psychiatric expertise is mandatory for persons who commit certain crimes: homicides, killing newborn children by the mother in the first hours of life (which is a self-contained crime in our Penal Code) and any felony committed by an underage. For other types of crimes, the police or the prosecutor will decide if a criminal offender will be subjected to a psychiatric expertise if they observe changes or strange elements in his behavior during the investigations.

The main goal of the legal psychiatric analysis is finding out if the criminal had discernment at the moment that he committed the misdemeanor and if he is able to take responsibility of his actions or not. Before discussing about discernment, we need to understand the essential concept of the psychiatric analysis: the mental capacity of exercising rights and responsibility. The mental capacity of exercising legal and civil rights refers to the ability of a person to assume obligations, to sign personal legal documents and to participate in legal terms. This concept can be examined on deceased people by examining that person's medical documents. For civil rights, the mental capacity starts at 18 years old in Romania and the penal right capacity which means penal liability begins at 16 years old but, between the age of 14 and 16, the underage can be legally punished if the experts prove that the 
felony was committed with discernment. Therefore, in Romania, a person can be responsible for criminal offences starting with the age of 14.

Responsibility is directly proportional with discernment and it is interconnected with the psychic capacity. Responsibility has two important definitions. According to the medical definition, it is the sum of psychic particularities that gives an individual the ability to understand his freedom and necessity of actions and to asses correctly the consequences of his actions, if he is doing something against the social rules and law. Responsibility has 3 mandatory conditions: the existence of social and moral laws, the integrity of mental health and the absence of constraint, meaning the freedom to do those actions without being forced by someone.

The determination of responsibility has two psychological characteristics: cognition (perception, reasoning, knowledge), affective features (emotions, feelings) and features such as impulses, wishes and will. According to law, responsibility refers to the ability of an individual to be held responsible for a crime. It is directly connected to guilt and intention which are the main characteristics of discernment. The notion "guilt" is seen in two ways in Romanian law system. It can refer to the direct guilt, in which case, a person commits an antisocial act with intention, anticipating the consequences of his actions and following the steps to achieve that result and it can also refer to the indirect guilt which has two varieties: the "easy guilt" where the person anticipates the result of his antisocial act but does not accept it and the "fault", where the person, in a certain circumstance, does not anticipate the result of his actions although he has the capacity to understand the danger of his actions. The lack of responsibility, on the other hand, is defined as the inability of an individual to understand the course of his actions at the moment that he or she produces an antisocial act; that person does not understand why his actions represent a social danger and he or she cannot be punished as a normal person because the correction measures could not make him or her understand the mistakes he or she made and he or she could not be reintegrated in society. Therefore, responsibility depends on the mental capacity which is characterized by discernment (Gheorghiu 2006, 23).

The existence of discernment at the moment of committing a felony is the main goal of the medico-legal psychiatric committee. The law and the medicine have almost the same definition for discernment: it refers to psychological capacity of a person to correctly analyze the benefits and the danger of an action, to calculate the steps of an action and the course to achieve the wanted result, to conceive a plan, therefore, it is the ability to organize and motivate an action. Discernment is a characteristic of free will and respect for the social and moral rules in the society that one lives in. This function depends on two factors:

- The individual's personality structure. For this feature, the expertise has to establish the grade of intellectual development, the grade of education (general and professional), the state of family education and growth environment, the life experience of the subject and the medical history (such as factors that can affect the mental state permanently or temporary - organic cerebral factors, toxic substances abuse, trauma history)

- The structure of personal consciousness at the moment the subject committed the crime. Consciousness is the complex synthesis of psychological functions through which an individual integrates in his environment, fixes and associates information with judgment and thinking functions.

Consciousness can be affected at a given time by tiredness, psychoactive drugs or associated pathologies but also by psycho-pathological circumstances such as fear, isolation, blackmail, threat. There are four levels of consciousness that will be assessed during the expertise:

- The elemental knowledge that include the vigil level and the temporal and special orientation.

- The logical and operational knowledge that include intellectual, perceptive and thinking processes therefore the coherence of mentation and objective reflection of reality.

- The axiological knowledge refers to the option of an individual to select his or her own good and bad values from the current social and environmental criteria.

- The ethical knowledge is the ability of discerning good and bad consequences that some action can bring to society. 
According to these statements, responsibility is conditioned by discernment which is conditioned by the state of consciousness which depends to the four levels of knowledge of an individual. For the underage felons examination, the expertise is even more complex because it has to asses all levels and mental capacity of a personality in continuous development. In theory, the absence of the discernment is traduced by a disintegration between the elemental level and the logical and operation level of knowledge. In the same time, the altering of the axiological knowledge defines just a remissive discernment which can attenuate the circumstances for the subject (Gheorghiu, 2006, 26).

Discernment does not vary only because of the mental development but also inside of the same personality structure depending on external factors and internal conditions that change in a way or another, the circumstances of a certain situation. Not even the psychiatric diseases cannot be assimilated with the permanent absence of discernment because every evolution has periods of remission or decompensations and, depending on the stage of the disease, there can be actions for which the patient can be held responsible or not.

The role of the medico-legal psychiatric expertise is to assess whether the discernment is present, remissive or absent (abolished) by analyzing the individual psychological features and the circumstances in which he or she committed a felony. According to the presence of the discernment and according to the safety measures regulated by the Romanian Penal Code (2010), the committee will state if the subject is able to fully take responsibility of his or her actions before justice and he or she can be judged and punished by the law or, if he or she did not have discernment at the moment he or she produced the crime, he or she will be permanently hospitalized in a mental disorder institute or he or she will be forced to take a certain treatment with severe control from the medical and law institutions and with regular medical assessment. In the last option, the committee will decide the grade of public danger that the subject represents and will take a decision regarding that subject, according to that grade of risk.

The examination will be conducted in two stages:

- The characterization of the person, the description of the antisocial act and establishing a causal relationship between the features above and the mental capacity and the capacity of exercising his or her rights. The personality assessment will examine the biological, psychological and social components such as tendencies, consciousness and personal normal and pathological features. It has to find the motivation and the nature of the inner conflict. The review of the antisocial act that has been committed by the subject has a diagnostic role, meaning it will place the aggressiveness, reactivity and the conflict from normal to pathological.

- The determination of the causal relationship between the individual's personality features and the constitutive elements of the antisocial act at the moment of the crime (offences, alcohol ingestion, provocations, frustrations, physiological state, evolution of certain somatic or mental disease, ages, sex, education). The determination of the mental state at the moment of the committee's interview is part of a multi-axial diagnosis but it is of no use or interest for the law system.

The causal chain is a very important aspect in the entire practice of legal medicine. In the psychiatric expertise, the causal chain will assess the connection between the antisocial event and the medical and psychiatric analysis, between the objective and subjective symptoms that the subject presents, the correlations between the clinical examination and the special objective examination and correlations between the subject's personality and the constitutive elements of the crime.

\section{The report of the medico-legal psychiatric expertise}

Every report of psychiatric medico-legal expertise will answer to the police or prosecutor's questions and it is mandatory that all statements to be made clear and undeniable. Those conclusions are important for the law implementation, for the course of investigation and come with a very high grade of responsibility for the specialists in the committee. Usually, the main questions that have to be answered are:

- If the subject is well oriented to his self and to the environment;

- If the medical examinations reveals any alteration of the mental state that could affect the capacity of discern or control his own actions;

- If there is a mental disorder, how altered is the discernment due to that disease. 
- If the assessment reveals any information that can confirm the lack or diminished state of discernment at the moment of the crime and what medical safety measures are to be taken in this case;

- What is the grade of the social danger of the subject;

The committee will conduct the interview with the patient but will also analyse the documentation: the investigation report, the social and family report, all medical documentation from the subject's history. The specialists will analyse the crimes that the subject committed, the circumstances of the antisocial act and his or her response in those circumstances, his or her personal, medical and personal history (old or chronical pathologies, education, profession, family history, behaviour history, financial state and felony history). All these features will be part of a vast social cross examination.

Another big part of the expertise is the psychiatric examination. That part will assess all knowledge, affective, personality processes. The specialist will examine his or her general personality and the responses to severe stress factors by putting the subject in a tensioned situation and by reviving the conditions he or she produced the antisocial act. These statements will appreciate and will prognosticate a part of the diagnostic and the grade of aggressiveness, the state of adaptability, if he or she regrets the act or if he or she feels any guilt which is important in the eventual possibility of recovery.

An important aspect of the forensic psychiatric expertise is recognising the duplicitous behaviour. When an individual's manifestation deviates from normal and enters the legal area, that person will try to hide his true intentions so he or she can be perceived differently and eventually escape the punishment. The felon will play a role consisting in thoughts, feelings and gestures in front of the investigators and the medical committee. There are 2 sides of the duplicitous behaviour: simulation (the positive-inventive side) and dissimulation (the negative-inventive side).

1. Simulation can be a behaviour post-antisocial act in which case it can be solitary or associative, depending on the influence the subject is receiving or not from the environment. This type of simulation is often viewed on prisoners. Simulation can also be anterior to the antisocial act, in the goal of hiding the intentions and attenuate the circumstances of the act. Simulation has many sides. The creator side is defined as inventing a certain disease and behaving as a patient, simulating the symptoms of that disease or, it can go further to self-harming or suicide. Another side of simulation is the exaggerating one, in which case, the simulant amplifies or accentuates the symptoms of the disease he or she is suffering from. This feature can go up to meta-simulation which mean that the subject is cured but he or she will still accuse the symptoms and fake the pain or the mental affection. These sides of true simulation need to be differentiated from the false simulation, which is very rare and relative and the sinistrous which is a state of faking severe disease or pains or symptoms in order to claim certain benefits.

2. Dissimulation represents a motivated, premeditated and conscious act of hiding disease or morbid states in order to obtain certain benefits. Therefore, the dissimulator tries to fake normality. The duplicitous behaviour can be easily detected with specific repeated interviews and psychological testing (Mihalache and Buhaş 2007, 284).

It is very important that during the hospitalization of the subject, no treatment should be given to him or her. That is important for an objective and realistic examination and therefore, the most dangerous patients will be controlled and held in restricted areas of the mental institution with guards.

For the determination of personality and cognitive structure it is important to conduct psychological tests. The most important one is the IQ test that provides the most important information about the mental capacity and discernment. The medical system in Romania, classifies the mental retardation (which is a problem for the expertise) into 3 categories according to the IQ:

- Easy retard, between 50 and 69 points; in this case, the subject can be held responsible for certain actions. This category usually includes individuals with high aggressiveness and uncontrolled impulsiveness.

- The moderate retard, between 20 and 49 points;

- The severe retard, with an IQ smaller than 20 points. The patients in the last 2 categories are considered with no mental capacity of self-conducting, many of them being institutionalised. 
Other tests used in the medico-legal psychiatric expertise are: the Wechsler deterioration test, personality and affective tests (Szondi impulsivity test, the Rorschach ink drops test, the Luscher colour test, test for verbal association, thematic perceptions, the human or tree tests, etc.). The Mini Mental - MMSE test is used to evaluate the severity of the cognitive dysfunction. It examines the language, orientation, attention, calculations and information reproduction processes and when it is pathological, the results are classified into easy deterioration with 21-30 points, moderate deterioration with 10-20 points and severe deterioration with a score smaller than 10 points. Also, the patients in the last 2 categories are considered to have no responsibility for their action. The psychiatric and psychological examination are completed by special tests such as EEG, MRI, CT and neurological examinations (Mihalache and Buhaş 2007, 284).

The finals stage of the examination is the interview with the patient in the presence of the legal medicine doctor, with the psychologist and psychiatric specialist that attended him during hospitalisation.

The expertise report is ended with the conclusions that will be signed by all the specialist that took part in the committee. The conclusions will answer the questions of the police or prosecution but there are also some specific statements present there: if the subject is or is not suffering from a mental illness and the grade of alteration on the mental state due to that disease, the causal link between the mental state and the antisocial act and whether or not, the subject had discernment at the time of producing that antisocial act, the alteration of mental health at the present time and the capacity of the subject to be judged and punished and if not, if he or she should be permanently hospitalised in a mental disorder institution or forced to take a certain treatment for a certain period of time, with regular medical examinations. The specialists will take into consideration if any further discussions will be stated in the report and if any other information is important for the investigators or for the law enforcing institution.

\section{Conclusions}

The medico-legal psychiatric expertise in Romania is regulated by the Penal Code and the Penal Procedure Code and it is organised in a committee formed by psychiatrists, psychologists and legal medicine doctors. The goal of this committee is to find out whether or not, a felon had discernment at the moment that he or she acted against social and law rules and, if he or she can be held responsible in front of the law system.

There are mandatory forensic psychiatric examinations, in the case of severe crimes against life, homicide of the new born children by their mothers in the first hours of life and felonies produced by underage persons. There are cases, when, the investigators will demand a psychiatric expertise, if they consider in the course of investigations, that the report is necessary.

The expertise is a very important medical criteria that is meant to offer the justice system a solution to a certain cause and a correct punishment for the criminal.

Responsibility of an individual is interconnected with the psychologic capacity, it depends on the discernment which is dependent on consciousness.

Discernment in the psychiatric expertise can be present, abolished and remissive and the examination is a complex synthesis of the circumstances of the antisocial act, the response of the individual in those particular stress environment, the mental state of the subject, the personality features and socio-familial features.

The absence of the discernment is traduced by a disruption in the elemental level and the logical and operation level of knowledge. In the same time, disruptions of the axiological knowledge will conclude in a remissive discernment which can attenuate the circumstances for the subject but these cases are very rare.

Not all the psychiatric diseases can be assimilated with the permanent absence of discernment because every evolution has periods of remission or decompensations and, depending on the stage of the disease, there can be actions for which the patient can be held responsible or not.

Duplicitous behavior is a constant fact during medico-legal expertise and it is important to correctly differentiate this behavior from the pathological one. 
The conclusions of the expertise report will also recommend safety measures for the subjects that cannot be held responsible for their actions. In this case, the committee will decide, according to the mental disorder and the grade of public danger that the subject represents, whether he or she will be hospitalized in a mental illness center or if he or she will be forced to take a treatment under strict surveillance.

\section{References}

Gheorghiu V, 2006, Medicina Legala - Note de curs, București, UMF "Carol Davila.

Mihalache G, Buhaș C, 2007, Dificultăți în redactarea constatărilor și expertizelor medico-legale, Iași, Rom J Leg Med.

The Penal Procedure Code of Romania, 2010, Law no. 135/2010, published in the Official Gazette of Romania, O.G. no. 486 on July 15, 2010. 